Jose M. Carnate, Jr., MD

\section{Department of Pathology}

College of Medicine

University of the Philippines Manila

Correspondence: Dr. Jose M. Carnate, Jr. Department of Pathology

College of Medicine, University of the Philippines Manila

547 Pedro Gil St. Ermita, Manila 1000

Philippines

Phone (632) 5264550

Telefax (632) 4003638

Email:jmcjpath@gmail.com

The author declared that this represents original material that is not being considered for publication or has not been published or accepted for publication elsewhere, in full or in part, in print or electronic media; that the manuscript has been read and approved by the author, that the requirements for authorship have been met by the author, and that the author believes that the manuscript represents honest work.

Disclosures: The author signed a disclosure that there are no financial or other (including personal) relationships, intellectual passion, political or religious beliefs, and institutional affiliations that might lead to conflict of interest.

\section{Low-Grade Cribriform Cystadenocarcinoma of the Parotid Gland}

This is the case of a 44-year-old woman with a one-year history of a left pre-auricular mass. The surgical specimen is a 5 centimeter diameter tan-brown irregularly-shaped tissue whose cut surfaces are brown with cystic spaces. Microscopic sections show cystic and dilated ductal spaces lined by cells forming irregular, variably-sized secondary spaces. These spaces are arranged in a cribriform pattern that is reminiscent of breast ductal hyperplasia. (Figure 1) The ductal cells lining the spaces are small, multilayered, and generally bland. The superficial cells show apocrine-type cytoplasmic snouting. There is no significant nuclear atypia or mitotic activity noted. Necrosis is also absent. (Figure 2) Based on these features, we signed the case as a low-grade cribriform cystadenocarcinoma (LGCCC).

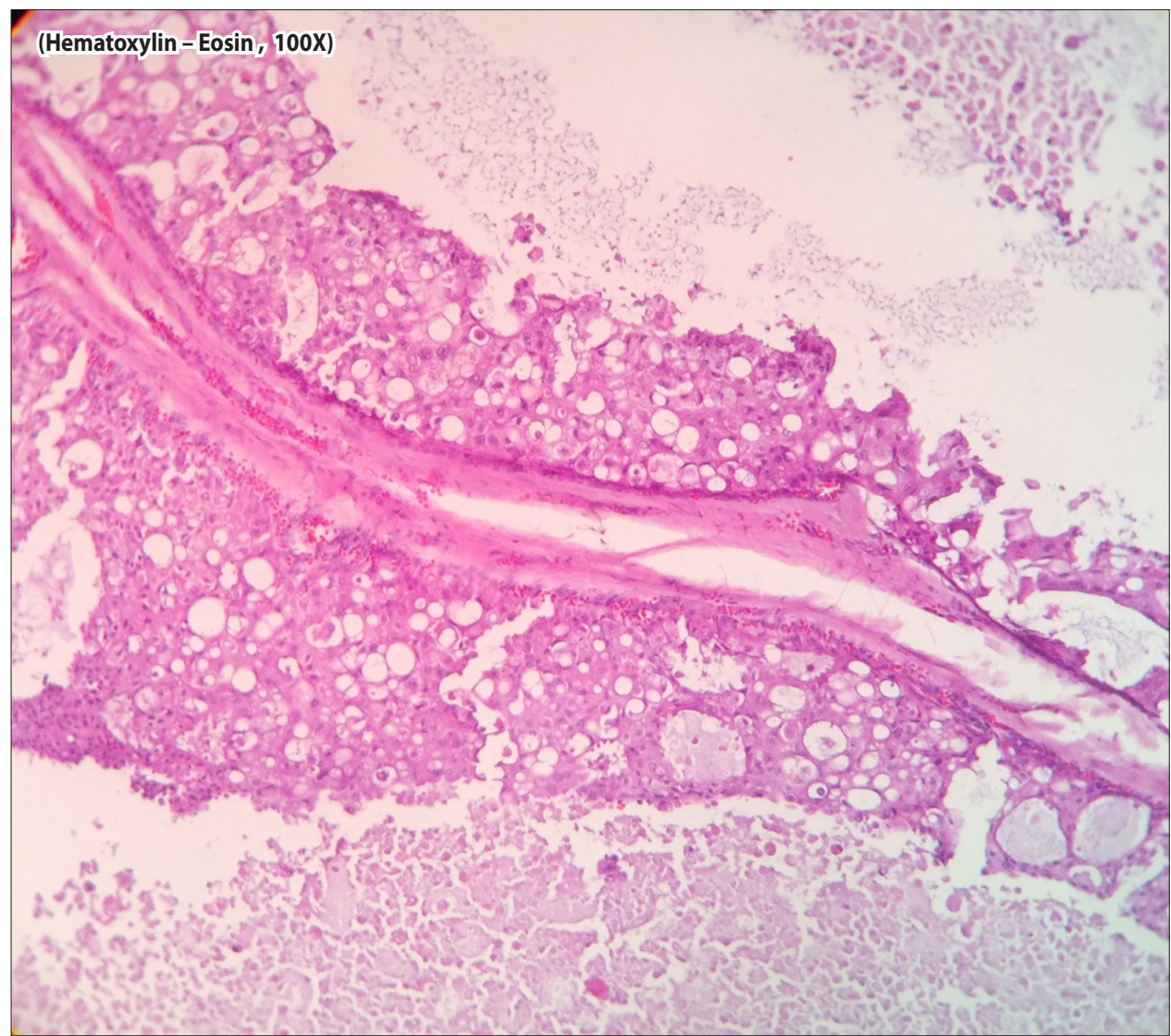

Figure 1. Dilated ductal spaces with cribriform structures reminiscent of breast ductal hyperplasia (Hematoxylin-eosin, 100X magnification) 


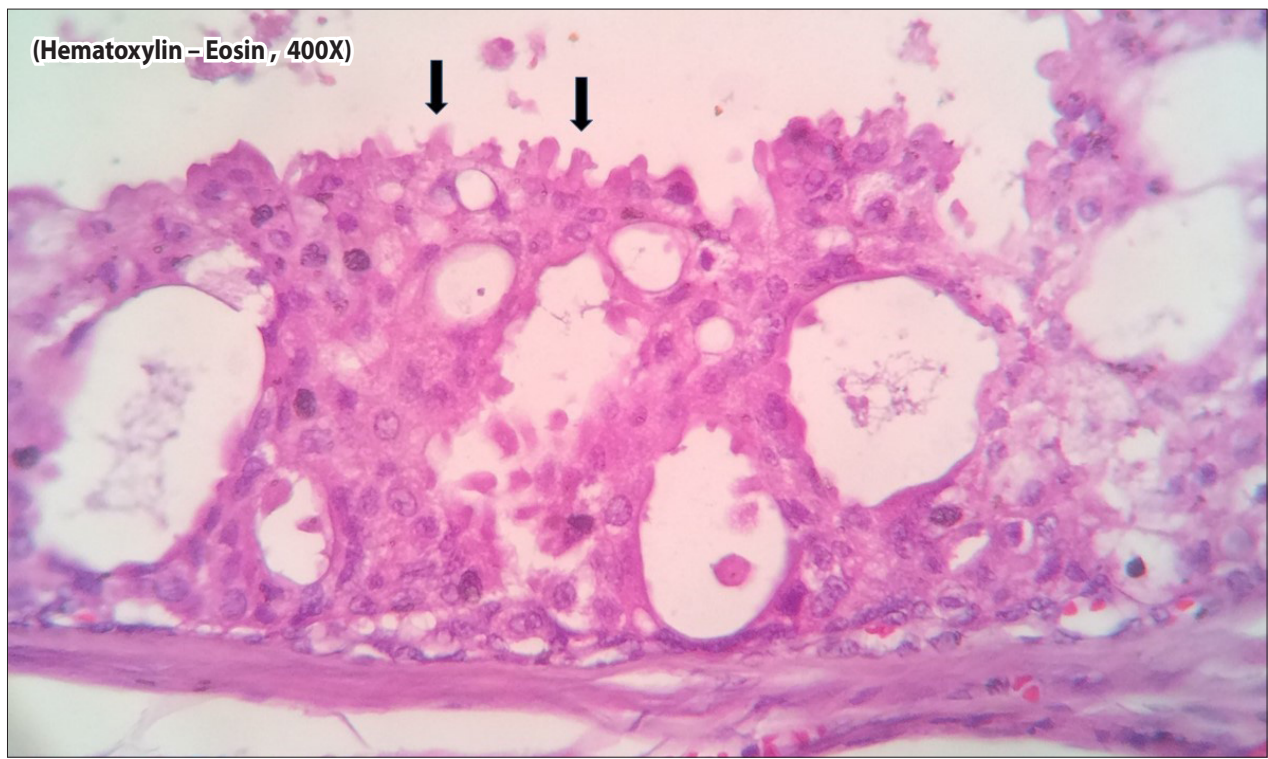

Figure 2. Bland ductal cells forming cribriform spaces. Superficial cells display apocrine-type snouting (arrows) (Hematoxylin-eosin, 400X magnification).

LGCCC is an uncommon tumor presenting primarily as cystic parotid masses in elderly females. The histologic hallmark of this tumor is its morphologic resemblance to the spectrum of breast lesions ranging from ductal hyperplasia to low-grade ductal carcinoma-in-situ. ${ }^{1-4}$

Microscopic sections show an unencapsulated tumor consisting of single or multiple cysts lined by proliferated small and bland ductal cells with fine chromatin and small nucleoli. Within the cystic spaces, the cells are often arranged in a cribriform pattern with anastomosing intracystic micropapillae lining the cavity. Many superficial cells show apocrinetype secretions. Thus, the over-all appearance is quite comparable to breast lesions that are termed atypical ductal hyperplasia and low-grade ductal carcinoma-in-situ. ${ }^{1-4}$ Focal invasion into the surrounding tissue can be seen. Perineural or vascular invasion however is typically absent. Cellular pleomorphism and mitoses are also usually absent and necrosis is rare. Occasional tumors however may demonstrate a transition to an intermediate or high-grade cytology with the appearance of scattered mitoses and focal necrosis. ${ }^{1,2}$

This tumor needs to be distinguished from a conventional cystadenocarcinoma. The latter is a more frankly invasive tumor with smaller duct-like structures that infiltrate into the salivary parenchyma and surrounding connective tissue. A papillary-cystic variant of acinic cell carcinoma will have areas of acinar differentiation and a greater degree of epithelial proliferation. ${ }^{1,5} \mathrm{~A}$ high-grade salivary duct carcinoma will have a high-grade cytology with more frequent necrosis, mitoses, and pleomorphism. ${ }^{6}$ Special stains that help in the differential diagnosis include Periodic Acid-Schiff(PAS) stain with Diastase digestion (diastase-resistant cytoplasmic granules in an acinic cell carcinoma), and S100 (strong diffuse positivity in LGCCC).

LGCCC is treated by complete surgical excision. Although there are only a few reported cases with follow-up, to our knowledge, none, to date, have recurred. ${ }^{1-4}$ 